\title{
3066 consecutive Gamma Nails. 12 years experience at a single centre
}

\author{
Alicja J Bojan*+1, Claudia Beimel+2, Andreas Speitling², Gilbert Taglang ${ }^{3}$, Carl Ekholm and Anders Jönsson ${ }^{1,2}$
}

\begin{abstract}
Background: Fixation of trochanteric hip fractures using the Gamma Nail has been performed since 1988 and is today well established and wide-spread. However, a number of reports have raised serious concerns about the implant's complication rate. The main focus has been the increased risk of a subsequent femoral shaft fracture and some authors have argued against its use despite other obvious advantages, when this implant is employed.

Through access to a uniquely large patient data base available, which is available for analysis of trochanteric fractures; we have been able to evaluate the performance of the Gamma Nail over a twelve year period.

Methods: 3066 consecutive patients were treated for trochanteric fractures using Gamma Nails between 1990 and 2002 at the Centre de Traumatologie et de l'Orthopedie (CTO), Strasbourg, France. These patients were retrospectively analysed. Information on epidemiological data, intra- and postoperative complications and patients' outcome was retrieved from patient notes. All available radiographs were assessed by a single reviewer (AJB).

Results: The results showed a low complication rate with the use of the Gamma Nail. There were 137 (4.5\%) intraoperative fracture-related complications. Moreover 189 (6.2\%) complications were detected postoperatively and during follow-up. Cut-out of the lag screw from the femoral head was the most frequent mechanical complication (57 patients, 1.85\%), whereas a postoperative femoral shaft fracture occurred in 19 patients (0.6\%). Other complications, such as infection, delayed healing/non-union, avascular femoral head necrosis and distal locking problems occurred in 113 patients (3.7\%).

Conclusions: The use of the Gamma Nail in trochanteric hip fractures is a safe method with a low complication rate. In particular, a low rate of femoral shaft fractures was reported. The low complication rate reported in this series can probably be explained by strict adherence to a proper surgical technique.
\end{abstract}

\section{Background}

The Gamma Nail was developed for the treatment of trochanteric hip fractures in the mid 1980's and was first brought into clinical use in 1988. The method of intramedullary nailing evolved from the concepts of Gerhard Küntscher to treat trochanteric fractures [1]. The Gamma Nail development started coincidentally in two places in independent and in parallel processes. It was developed in Halifax, UK, in an attempt to overcome some of the clinical problems with the Zickel nail [2,3] an intramedullary implant used for the treatment of pathologic subtrochanteric fractures. Simultaneously, a

*Correspondence: alicja.bojan@vgregion.se

1 Department of Orthopaedics, Institute of Clinical Sciences at the Sahlgrenska Academy, University of Gothenburg, Gothenburg, Sweden

+ Contributed equally

Full list of author information is available at the end of the article similar implant for same indications was developed at the CTO, Strasbourg, France. These two projects were merged and after a number of clinical evaluations and modifications to both implants and instruments, by 1988 one design emerged designated hereafter as "The Standard Gamma Nail" (SGN).

"The Long Gamma Nail" (LGN) was introduced in 1992 and is used for subtrochanteric hip fractures, femoral shaft fractures and combined trochantero-diaphyseal fractures of the femur. A modified design of the SGN, named "The Trochanteric Gamma Nail" (TGN), was introduced in 1997 and subsequently replaced the SGN.

Today the use of the Gamma Nail is widespread, with more than million patients treated since the introduction of the implant. This is due to several perceived advantages, such as minimal invasive technique allowing for 
short skin incisions and less blood loss compared with other techniques requiring more surgical exposure [3-6], reduced infection rate, minimal tissue damage, a shorter operating time and early weight bearing $[7,8]$. The intramedullary position of the Gamma Nail provides a short lever arm for the cephalic screw, still allowing controlled impaction of the fracture [3,4,9-14], but probably with less shortening than with sliding hip screw systems [15].

Despite the widespread use of the Gamma Nail, there are reports on complications that are claimed to be implant-design related $[14,16]$. The use of the implant has been widely debated because postoperative complications such as subsequent shaft fractures [6,17-19] and lack of scientific evidence supporting intramedullary versus extramedullary technique [3,5,13,20-34]. Nevertheless, this implant has seen numerous competitors [35-41] based on the same concept, i.e. antegrade intramedullary nailing.

We decided to perform a thorough investigation of the Gamma Nail performance over a long period of time focusing on complications. At the Centre de Traumatologie et de l'Orthopedie (CTO) in Strasbourg, France we had access to a large database of thousands of consecutive patients treated with Gamma Nails. In the time period 1990-2002, 3066 consecutive patients treated with Gamma Nails were identified and retrospectively evaluated.

\section{Methods}

The present study is a retrospective analysis of every patient treated with a Gamma Nail at CTO between January 1990 and December 2002. All patients with basocervical (AO/ASIF 31-B2.1), trochanteric (AO/ASIF 31-A), subtrochanteric (AO/ASIF 32-A) or combined trochantero-diaphyseal fractures (Table 1) entering the hospital (CTO) were treated with a Standard Gamma Nail (SGN),

Table 1: Fracture distribution according to the AO/ASIF fracture classification.

\begin{tabular}{ccc}
\hline AO/ASIF class & Count & Frequency (\%) \\
\hline $31-\mathrm{A} 1$ & 965 & 31.5 \\
$31-\mathrm{A} 2$ & 1080 & 35.2 \\
$31-\mathrm{A} 3$ & 371 & 12.1 \\
$31-\mathrm{B} 2$ & 170 & 5.5 \\
$32-\mathrm{A}$ & 114 & 3.7 \\
$32-\mathrm{B}$ & 49 & 1.6 \\
Other & 40 & 1.4 \\
Missing & 277 & 9.0 \\
Total & 3066 & 100 \\
\hline
\end{tabular}

a Trochanteric Gamma Nail (TGN) or a Long Gamma Nail (LGN). A small number of patients received another type of Gamma Nails (Gamma-Ti Nail, Long Gamma-Ti Nail, Dyax Asiatic Nail). No other implants were used for these types of fractures during this period. The implants were purchased from Howmedica France S.A. and from 1999 onwards from Stryker France S.A.

The patients were treated as surgical emergencies and the procedures were performed both by doctors under training and by senior surgeons. All surgeons were trained for the procedure.

The patients were operated on a traction table in a supine position, both general and spinal anaesthesia were used. Image intensifier was used. Additional fixation such as screws, cerclage wires and bone grafting was used when needed. Full weight bearing was allowed immediately postoperatively, except when the patient was believed to have an insufficiently stable fixation. Radiological examinations were performed pre-operatively, postoperatively within 24 hours after surgery and at follow-up when indicated.

The data collection was performed between $1^{\text {st }}$ of March and $30^{\text {th }}$ of June 2003 at CTO, Strasbourg, France. The study period was from the $1^{\text {st }}$ of January 1990 to the $31^{\text {st }}$ of December 2002. For these 12 years the data were collected for 3066 patients, all treated with Gamma Nails. A separate record of all patients treated with Gamma Nails was kept at the hospital. All available documents of these patients including radiographs were retrieved from the hospital archives. The demographic and technical intraoperative data were completed for all patients with help of the detailed list of all patients treated with Gamma Nail kept at the hospital since the introduction of this implant in the late 1980's.

The medical reports were reviewed for epidemiological data such as age, gender, fracture side, fracture aetiology, co-morbidity, pre- and postoperative mobility levels and presence of pain. Type of anaesthesia, nail type and nail dimensions were recorded. The intra- and postoperative complications were detected with the help of surgical reports, radiographs and follow-up visit notes. Patients were routinely scheduled for a follow-up visit usually between 3 and 6 months postoperatively. Institutionalised patients were reviewed at CTO only if needed.

The radiographs, antero-posterior and lateral views, were evaluated by a single observer (AJB). Pre-operative radiographs were used to classify the fractures according to the AO/ASIF system [42]. The fractures classified as 31-A1 were considered stable $[43,44]$.

Quality of fracture reduction was assessed on postoperative radiographs. For the reduction to be considered unsatisfactory there was misalignment on the anteroposterior radiograph of more than $10 \mathrm{~mm}$ of any fragment, $10^{\circ}$ of varus/valgus angulation, and/or more than 
$20^{\circ}$ of angulation on the lateral radiograph. Displacement of the lesser trochanter was disregarded.

Delayed union was defined as persistent pain and no sign of bridging callus after 4 months postoperatively. Non-union was defined as persistent pain and no sign of bridging callus 6 months postoperatively [45]. Avascular femoral head necrosis (AVN) was defined as pain over the groin on weight-bearing correlated with radiographic findings: subchondral fracture, segmental or total collapse of the femoral head accompanied by secondary osteoarthritic changes [46]. Revision as a cause for surgery has been defined as a secondary surgery with Gamma Nail following a failure of previous fixation in trochanteric fracture. Traffic accident and fall from height as fracture cause was defined as high-energy trauma.

The records for mean operating time, the intraoperative blood loss, and the level of surgeon experience were incomplete and not retrievable.

The following complications were recorded: general complications defined as medical and anaesthetic complications during surgery, technical complications during surgery, and postoperative complications defined as fracture-related problems after surgery.

The institutional review board at CTO gave ethical approval before the study was commenced. Due to the retrospective nature of the study no burden or risk was imposed on the patients.

\section{Statistical analysis}

Results were tabulated and statistically analysed by using the SPSS (version 11.5, SPSS Inc. Chicago, Illinois, USA). The case report form and the corresponding variables were uniquely generated for our patient population and the questions adapted with help of patient notes samples before starting the study. Frequency and percent distributions were presented in tabular form for categorical variables. When data were missing, the remaining set of patients has always been validated by sex and age versus the total group of patients and when appropriate also for fracture pattern or fracture cause. Comparative analysis was performed by using the Chi-Square test for nominal and ordinal variables by evaluating frequencies within the groups with the method of cross tabulation. Before analysing continuous variables, the data sets were tested for normality by performing the Shapiro-Wilk test. When distribution was considered to be normal, for independent samples the Student's T test was performed; otherwise the Mann-Whitney test was used. Statistical significance for all tests was set at p-values less than 0.05 . For normally distributed continuous variables, mean values, standard deviations (SD) and 95\% confidence intervals (CI) of the mean are shown. For non-normal distributed continuous variables, median, range and interquartile ranges (IQR) are displayed.

\section{Results \\ Demographics}

In total, 3066 consecutive patients treated with Gamma Nails were identified. Of these 2255 were women (73.5\%), ratio female: male 2.7. Median age was 81 years, ranging from 14 to 106 years, with an IQR of 16 years. In the overall patient population as well as in most of the subgroups, the variable "age" showed always a significantly skewed distribution ( $\mathrm{p}<0.001$, Shapiro-Wilk Test).

The proportion of females and males did not change over the years. Left-sided fractures were present in 50.7\% of the patients. For both genders, the number of fractures increased with age to peak between 81 and 90 years. In age groups 11-60 years males were predominant (ratio female/male 0.4). $53.0 \%$ of all male fractures occurred before the age of 70 , but only $13.8 \%$ in women.

Three dominant fracture causes were identified: a simple fall (88.1\%), road traffic accident (5.1\%), fall from a height (3.0\%) and other causes (3.8\%). Traffic accidents were responsible for fractures in $44.0 \%$ of the patients up to the age of 40 , after this age a simple fall was the most common cause for both genders. High-energy trauma accounted for $7.2 \%$ of all fractures and $1.5 \%$ of fractures were seen in multitrauma patients. Ten patients had open fractures.

The fracture aetiology did not change during the study period. Males in all age groups were more likely than females to sustain a fracture from high-energy trauma (traffic accident or fall from a height) $21.3 \%$ vs. $2.3 \%$ ( $\mathrm{p}<$ 0.001 ). This is most obvious in ages under 21 where none of the female fractures were due to traffic accidents (Table 2). In absolute numbers, high-energy fractures were fairly constant within males up to age of 70 years, varying between 24 and 37 patients annually (Table 3 ). Low energy fractures were the most common fracture cause after the age of 50. In females the rate of highenergy fractures in all age groups was low and its contribution is obscured by the dramatic increase in fragility fractures after the age of 70 (Figures 1 and 2). Nevertheless, $46.0 \%$ of female high-energy fractures occurred in ages 61-80 years.

Stable fractures (AO/ASIF 31-A1) constituted about one third of all fractures and grossly unstable fractures (AO/ASIF 31-A.3) constituted 12.1\% (Table 1). Males were slightly overrepresented with unstable fractures. Patients under the age of 60 were more likely to sustain an unstable fracture than patients over $70(62.5 \%$ vs. $59.6 \%, \mathrm{p}<0.005)$. The fracture distribution did not show any yearly variations.

On admission, $26.3 \%$ of the patients had no other medical condition, $34.2 \%$ had one co-existent disease, and 
Table 2: Distribution of injury cause in age groups in women.

\begin{tabular}{|c|c|c|c|c|c|c|c|c|c|}
\hline $\begin{array}{c}\text { Age } \\
\text { groups }\end{array}$ & Traffic & $\begin{array}{c}\text { Fall from } \\
\text { height }\end{array}$ & Simple fall & Revision & Metastasis & Other & Missing & Total & $\%$ \\
\hline $11-20$ & 0 & 0 & 1 & 3 & 0 & 1 & 0 & 5 & 0.2 \\
\hline $21-30$ & 5 & 1 & 0 & 2 & 0 & 0 & 4 & 12 & 0.5 \\
\hline $31-40$ & 3 & 2 & 3 & 0 & 3 & 1 & 1 & 13 & 0.6 \\
\hline $41-50$ & 2 & 5 & 14 & 0 & 3 & 1 & 2 & 27 & 1.3 \\
\hline $51-60$ & 4 & 1 & 32 & 1 & 12 & 2 & 9 & 61 & 2.7 \\
\hline $61-70$ & 10 & 4 & 147 & 5 & 11 & 1 & 15 & 193 & 8.6 \\
\hline $71-80$ & 7 & 3 & 533 & 9 & 12 & 3 & 24 & 591 & 26.2 \\
\hline $81-90$ & 2 & 3 & 946 & 13 & 7 & 3 & 69 & 1043 & 46.2 \\
\hline $91-100$ & 0 & 0 & 287 & 2 & 3 & 1 & 15 & 308 & 13.6 \\
\hline $101-110$ & 0 & 0 & 2 & 0 & 0 & 0 & 0 & 2 & 0.1 \\
\hline Total & 33 & 19 & 1965 & 35 & 51 & 13 & 139 & 2255 & 100 \\
\hline$\%$ & 1.3 & 1.0 & 87.1 & 1.5 & 2.3 & 0.6 & 6.2 & 100 & \\
\hline
\end{tabular}

$36.3 \%$ had 2-3 additional medical conditions, while $3.2 \%$ had more than 3 co-diseases. Almost half of the patients (48.0\%) were socially independent. A prior contra-lateral hip implant was present in $10.2 \%$ of the patients.

\section{Treatment}

The SGN was implanted in 1623 patients, the TGN in 933 patients and LGN in 473 patients. In 37 patients other nail types were used (Gamma-Ti Nail, Long Gamma-Ti Nail, Dyax Asiatic Nail). The LGN patients were significantly ( $\mathrm{p}<0.001$ ) younger (median age 70 years, range 14 to 98 years, IQR 35 years) compared to patients in the SGN/TGN group (median age 82 years, range15 to 106 years, IQR 14 years). Furthermore, the LGN patients had, to a higher degree, sustained high-energy fractures ( $\mathrm{p}<$ 0.001): traffic accidents (16.3\%) and fall from height (9.4\%). 20.1\% of LGNs were used in pathological fractures and $8.6 \%$ for revision surgeries.

Fracture reduction was considered by the investigator to be satisfactory in $84.7 \%$ and unsatisfactory in $5.7 \%$ of cases, information for $9.6 \%$ was missing. In only three patients an open reduction was performed. According to the surgical notes, the surgeon found insertion of the nail to be difficult for $3.1 \%$ of the nails in the SGN group, $1.0 \%$ in TGN group and 5.3\% in the LGN group. In $4.1 \%$ of all patients distal locking was not performed because of perceived good stability of the fracture or accidentally by missdrilling. Enhanced fixation (screws, cerclage wires,

Table 3: Distribution of injury cause in age groups in men.

\begin{tabular}{|c|c|c|c|c|c|c|c|c|c|}
\hline $\begin{array}{c}\text { Age } \\
\text { groups }\end{array}$ & Traffic & $\begin{array}{c}\text { Fall from } \\
\text { height }\end{array}$ & $\begin{array}{c}\text { Simple } \\
\text { fall }\end{array}$ & $\begin{array}{c}\text { Revisio } \\
\text { n }\end{array}$ & $\begin{array}{c}\text { Metast } \\
\text { asis }\end{array}$ & Other & Missing & Total & $\%$ \\
\hline $11-20$ & 14 & 1 & 1 & 0 & 0 & 0 & 0 & 16 & 2.0 \\
\hline $21-30$ & 20 & 5 & 2 & 8 & 0 & 2 & 3 & 40 & 5.0 \\
\hline $31-40$ & 22 & 12 & 12 & 3 & 0 & 1 & 9 & 59 & 7.3 \\
\hline $41-50$ & 22 & 15 & 26 & 6 & 4 & 5 & 4 & 82 & 10.1 \\
\hline $51-60$ & 11 & 11 & 42 & 4 & 7 & 3 & 10 & 88 & 10.8 \\
\hline $61-70$ & 14 & 10 & 98 & 4 & 9 & 5 & 6 & 146 & 18.0 \\
\hline $71-80$ & 5 & 6 & 139 & 5 & 5 & 0 & 12 & 172 & 21.2 \\
\hline $81-90$ & 1 & 4 & 148 & 3 & 1 & 1 & 13 & 171 & 21.1 \\
\hline $91-100$ & 0 & 0 & 33 & 0 & 0 & 0 & 3 & 36 & 4.4 \\
\hline $101-110$ & 0 & 0 & 1 & 0 & 0 & 0 & 0 & 1 & 0.1 \\
\hline Total & 109 & 64 & 502 & 33 & 26 & 17 & 60 & 811 & 100 \\
\hline$\%$ & 13.4 & 7.9 & 61.9 & 4.1 & 3.2 & 2.1 & 7.4 & 100 & \\
\hline
\end{tabular}




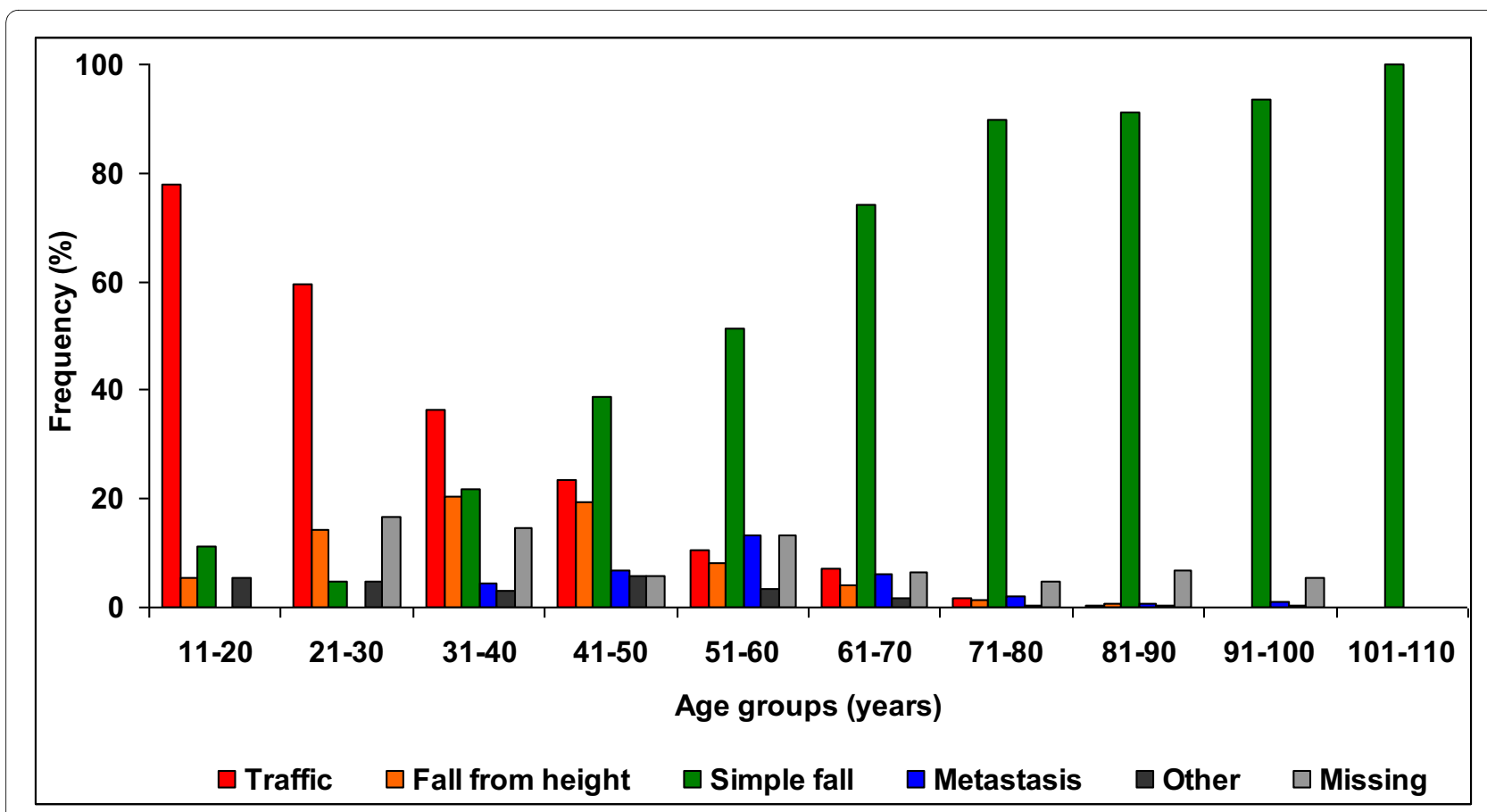

Figure 1 Relative fracture cause distribution in age groups for both genders

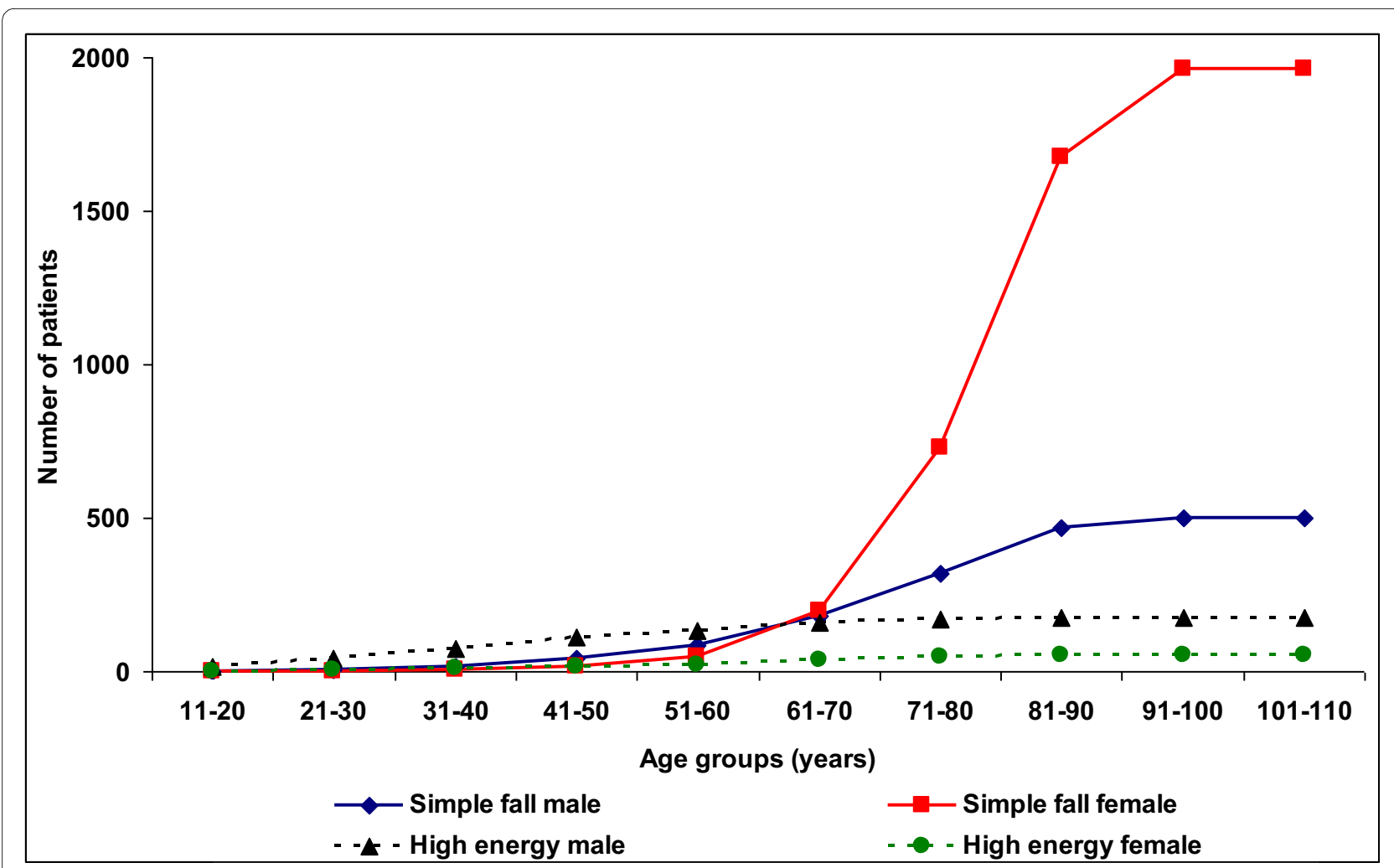

Figure 2 Comparison of cumulative incidence in high-energy trauma vs. simple fall in age groups for both genders. 
bone grafting) was used in 17 patients (0.6\%). In 18 patients $(0.6 \%)$ the fixation was believed to be insufficiently stable and full weight bearing was not allowed.

At discharge, $6.2 \%$ of the patients were sent home and required no additional assistance. Twenty percent were discharged to home with nursing or to a rehabilitation institution $(37.1 \%)$ or a nursing home $(22.6 \%)$. The rest (14.3\%) were sent to other institutions as dictated by other medical conditions. One-hundred-and-forty-one patients (4.6\%) died before hospital discharge.

\section{General complications}

Altogether, 172 general complications (5.6\%) were identified. Five patients had severe intraoperative complications related to anaesthesia; one of them deceased during surgery. One-hundred-and-sixty-seven complications (5.4\%) were recorded postoperatively: 119 cardio-respiratory problems, 13 lung embolisms, 12 deep vein thromboses and 23 other medical complications (e.g. sepsis, renal insufficiency or stroke).

\section{Intraoperative fracture related complications}

We observed 137 (4.5\%) fracture related complications during operation. Difficulties with distal interlocking resulted in additional perforations of cortices or placement of the distal locking screw outside the nail in 104 patients (3.4\%). Thirty-one of these occurred with free hand distal interlocking in LGNs. Targeted distal nail locking in short nails (SGN and TGN) resulted in 8.6\% misdrillings until 1993. With the introduction of a new radiolucent targeting device in 1994, the rate of this complication dropped significantly to $1.1 \%(\mathrm{p}<0.001)$.

Intraoperative fractures were noticed in 17 cases $(0.5 \%)$ (10 SGNs, 1 TGN and 6 LGNs). Thirteen intraoperative fractures occurred in the lateral cortex of the proximal femur (9 SGN, 1 TGN and 3 LGN). Another four patients sustained distal anterior cortical perforation by the tip of the nail (3 LGN, 1 SGN). In five of these 17 cases the surgeons noticed an aberrant shape of the femur due to rachitic deformity, Paget's disease or trisomy 21 syndrome.

Sixteen surgeon-related problems were recorded; malreduction of the fracture or poorly positioned implant in 12 patients that led to second surgical procedure to avoid later complications, guide wire perforation into the pelvis in two cases, lag screw perforation into the acetabulum in one case and one case of lost set screw in the soft tissue.

\section{Postoperative fracture related complications}

Postoperatively and during follow-up 189 complications (6.2\%) were detected (Table 4). We observed 19 postoperative femoral shaft fractures $(0.6 \%)$. Thirteen of the 19 occurred with SGN, five with TGN and one with LGN. Fifteen were observed within less than three months postoperatively. One fracture was revised with a GK fem- oral nail and the others with LGN. Correlation between femoral shaft fractures and distal locking problems, age, fracture pattern or nail type could not be shown. There were nine cases of distal interlocking screw problems (screw breakage and screw backing out). In total, statistically significant fewer complications were seen in the TGN group compared with the SGN group. There were 105 patients (6.5\%) in SGN and 32 patients (3.3\%) in TGN group $(\mathrm{p}<0.001)$.

\section{Implant removal}

Two-hundred-and-twenty-nine implant removal procedures were carried out. Eighty-seven nails were removed because of the complications described above. These patients were significantly $(\mathrm{p}<0.001)$ younger (median age 73 years, range 30 to 93 years, IQR 22 years) than rest of the study group. Persistent pain warranted nail removal in 30 patients, in four cases distal locking screws were removed and in two cases the lag screw was exchanged. Additionally 106 nails (3.4\%) were removed for reasons other than complications (patient desires, low age). The LGN was removed most frequently $(11.8 \%)$, followed by SGN (2.3\%) and TGN (1.3\%). The nails were removed in $9.6 \%$ of males and only in $1.2 \%$ of females; this difference being strongly statistically significant $(\mathrm{p}<$ 0.001). Considering fracture type, Gamma Nails were removed in complex diaphyseal fractures (AO/ASIF 32C) most frequently, 15 out of 25 implants (60\%), followed by subtrochanteric and simple diaphyseal ones (AO/ASIF 32-A and $\mathrm{B}, 16 / 158,10.1 \%)$, complex intertrochanteric (AO/ASIF 31-A3.3, 19/229, 8.3\%) and simple intertrochanteric ones (AO/ASIF 31-A3.2, 6/78, 7.7\%).

Without new trauma, eight fractures occurred in the trochanteric region within two weeks after nail removal in healed fractures. These patients were significantly $(\mathrm{p}<$ 0.001 ) younger (median age 58 years, range 20 to 77 years, IQR 32 years) than the rest of the study group. In three cases, the re-fracture followed the primary fracture line.

\section{Discussion}

The most important finding of the present study is the low rate of fracture related complications with the use of the Gamma Nails in the treatment of trochanteric hip fractures compared with the literature [16,20,47-49].

In the present study, the rate of a subsequent fracture of the femoral shaft was extremely low (0.6\%). Cut-out through the femoral head and AVN that led to revision were seen at a rate of $1.4 \%$. General medical complications were seen in $5.6 \%$ of the patients, which is comparable with other studies $[29,49]$.

Fracture of the femoral shaft is a serious complication that has been reported more frequently for the Gamma Nail than with other devices used for the treatment of 
Table 4: The analysis of fracture-related postoperative complications and their treatment.

\begin{tabular}{|c|c|c|c|c|}
\hline $\begin{array}{l}\text { Fracture related postoperative } \\
\text { complication }\end{array}$ & Number of patients & Frequency (\%) & Treatment & $\begin{array}{c}\text { Number of } \\
\text { patients }\end{array}$ \\
\hline \multirow[t]{5}{*}{ Cut out } & 57 & 1.85 & THR & 17 \\
\hline & & & Nail change & 5 \\
\hline & & & Nail removal & 8 \\
\hline & & & Lag screw removal & 1 \\
\hline & & & No intervention & 26 \\
\hline \multirow[t]{4}{*}{ Infection } & 46 & 1.5 & Nail removal & 13 \\
\hline & & & Lavage & 6 \\
\hline & & & THR & 3 \\
\hline & & & No intervention & 24 \\
\hline Femoral shaft fracture & 19 & 0.6 & Long Gamma Nail & 19 \\
\hline \multirow[t]{3}{*}{ Avascular head necrosis } & 17 & 0.5 & THR & 10 \\
\hline & & & Nail removal & 1 \\
\hline & & & No intervention & 6 \\
\hline \multirow[t]{5}{*}{ Delayed healing/non-union } & 41 & 1.5 & Nail dynamisation & 32 \\
\hline & & & Bone grafting & 10 \\
\hline & & & Exchange nailing & 3 \\
\hline & & & THR & 2 \\
\hline & & & Set screw removal & 1 \\
\hline \multirow[t]{2}{*}{ Distal locking screw problems } & 9 & 0.3 & Screw removal & 2 \\
\hline & & & No intervention & 7 \\
\hline
\end{tabular}

trochanteric hip fractures. High incidence (6-17\%) of a femoral shaft fracture after Gamma nailing was observed in earlier studies $[6,14,50-52]$. It was believed that this was due to specifics of the nail design of the first generation Standard Gamma Nail, such as the length, the valgus curvature and the distal diameter. It has also been suggested that there is a disparity between the design of the nail and the geometry of the bone resulting in the increased stiffness of the bone-implant system [14,53]. Inappropriate placement of the distal locking screws [6] and/or misdrilling could also be responsible for some of these complications. Incorrect reaming or excessive tightening of the distal interlocking screws $[14,54]$ as well as the inappropriate handling of the implant such as the use of a hammer or insufficient reaming $[3,53,54]$ could increase the risk for this complication. These are factors, which can all be controlled by proper training and more surgical experience [28]. In addition, intraoperative fractures may have passed unnoticed to present later as a femoral shaft fracture [29].

In accordance with other studies [38,48], most of the femoral shaft fractures occurred within three months postoperatively. However, the low rate of femoral shaft fracture in the present study $(0.6 \%)$ is in contrast to other more recent reports on the SGN, e.g. 2.0\% [16], 5.0\% [48] or on other nail designs such as Proximal Femoral Nail (PFN, Synthes Switzerland); 2.0\% [49], Proximal Femoral Nail Alpha (PFNA, Synthes Switzerland): 2.2\% [55]. On the other hand in a study of 1000 patients [28] and in a study on the second-generation Gamma Nail (TGN) [5] this complication had a low rate of $1.1 \%$ and $0 \%$ respectively. A recent meta-analysis [56] clearly shows that newer design of the intramedullary devices and more surgical experience reduce the risk of the subsequent femoral shaft fracture.

We attribute the low rate of the postoperative femoral shaft fractures in this report to strict adherence to the original surgical technique at this study centre. Regardless of the implant, it appears that there is an increased rate of implant-related femoral shaft fractures after a hip fracture, particularly ipsilateral ones. The hip fracture population is fracture-prone and the consequences of a previous hip fracture such as diminished mental health score, altered hip- and femoral biomechanics, postoperative osteoporosis and increased likelihood of a new fall makes the patient susceptible to new injuries. It can therefore be assumed that there is a "baseline" level of postoperative femoral shaft fractures whatever method has been used to treat the hip fracture. This level appears to be in the range from $0 \%$ to $0.5 \%$ for nail fixation $[5,49]$ 
and between $0.6 \%$ [48] and $1.2 \%$ for plate fixation [57]. Incidence above this level may be due to specifics of the study group such as age, gender and fracture type or related to the choice of implant or the skills with which it is used. Despite the significant decrease in distal locking problems after the introduction of a new targeting device in 1993 we could not show a further decrease in postoperative femoral shaft fractures indicating that a proper technique was followed from the beginning. The study population at the CTO appears to have reached the baseline level for this complication.

In the present study, the complication responsible for the highest number of revisions was cut-out through the femoral head (1.85\%). The cut-out complication has been reported to be the most frequent mechanical mode of failure for internal fixation devices for treatment of trochanteric hip fractures [58-60]. The cut-out rate varies between 0 and $16 \%$ in the previous studies $[16,28,32,49,61]$ and in older studies even up to $20 \%$ [62]. In previous reports, the revision incidence for these complications varies depending on the implant, with the Gamma Nail seeming to have a lower revision rate than plate fixation (Osnes et al. [48] plate fixation: 2.2\%, SGN: 0.8\%, Miedel et al. [29]: Medoff-SHS: 5.5\%, SGN: 2.7\%). We therefore suggest that more attention should be paid to this complication, which may be surgically preventable $[16,63]$. The incidence of cut-out in our study $(1.85 \%)$ is comparable to the one reported by Kukla and co-workers (2.1\%) [28].

Although the rate of femoral shaft fractures did not decline over the study period other improvements were seen. The distal locking problems decreased significantly $(\mathrm{p}<0.001)$ after introduction of the second-generation targeting device at the end of 1993 (8.6\% in early group vs. $1.1 \%$ in the late group). Significantly fewer fracture related complications were seen in the TGN group compared to the SGN group $(\mathrm{p}<0.001)$. This probably reflects the newer design with increased anatomical conformity [14,53]. Apart from these improvements over time we could not find proof of a "learning curve" in contrast to other authors [28]. This may be explained by the CTO being the developing hospital for the use of the Gamma Nail, in particular the surgical technique, and has rigorously maintained the surgical principles and technique associated with the use of this implant.

Re-fracture of the trochanteric region was seen within two weeks after nail removal, for reasons other than revision, in eight patients (8/136 patients). The patients sustaining this complication were young (median age 58 years). Removal of the Gamma Nail should therefore be done with caution and the patient should be advised on partial weight bearing until consolidation $[16,28,29]$.

Our data has allowed us to specify the cause for each fracture in a detail, which we believe, is unique. Gender and age specific patterns were clearly seen. Males are more likely than females to have a high-energy fracture. It is obvious that this is explained by different activity and labour pattern, not only osteoporosis. Nevertheless, $46.0 \%$ of female high-energy fractures occur in ages above 60 , reflecting a high activity level in this age group. It is also striking that traffic accidents are the main cause for trochanteric fractures in the young up to the age of 40 years. The epidemiological data cannot be presented as incidence numbers, since we lack epidemiological background data for the catchment population. We have no reason to believe that it differs considerably from other countries in the region and data are in concordance with other reports $[64,65]$.

This is by far the largest patient cohort treated with the Gamma Nails. Over 3000 consecutive patients at a single centre over a period of twelve years were analysed. The study period stretches from shortly after the market introduction of the implant until 2002. This also gave us the possibility of comparing two design generations of the implant. An additional strength of the study is that all radiological assessments, such as fracture classification, quality of fracture reduction and implant positioning were performed by a single observer in a limited time period (four months) limiting intra- and inter-observer bias, despite a possible risk for some systematic error.

Intra- and postoperative patient's notes were missing for 185 cases (6.0\%). Only 1980 (64.6\%) patients had at least one follow-up entry in our database. This important loss to follow-up can be explained by the retrospective character of the study and the long study period with varying methods in data collection. High mortality after trochanteric fractures and difficult surveillance of patients living at nursing homes contributed to the amount of missing data.

The quality of the radiographs was too variable to allow reliable assessment of osteoporosis grading according to Singh index [66], or tip - apex distance (TAD) measurement [58]. However, evaluation of position of the lag screw in the femoral head was possible for 2610 cases (85\%).

The CTO had a defined patient catchment area increasing the likelihood for the return of the patients to the hospital, should a complication occur, thus enabling an accurate recording of postoperative events. Accordingly, it is unlikely that femoral fractures have been unreported particularly since these typically occur within three months after the primary operation $[16,48]$.

\section{Conclusions}

A number of patient-related factors predict the outcome after treatment of trochanteric hip fractures such as fracture geometry, age and gender of the patient [67] as well as dementia [68]. However, the surgeon is in control of 
fracture reduction, implant selection and implant placement, all of which must be optimized to ensure the success of the surgical intervention. We believe that this study supports the use of the Gamma Nail in trochanteric hip fractures leading to a low complication rate when the correct surgical technique is respected. As with any implant used for these fractures the main complication appears to be the cut-out of the lag screw through the femoral head, although at a low rate, while implantrelated femoral shaft fracture is less of the problem. Further evaluation of hip fracture treatment should involve multi-centre randomised prospective trials comparing cephalo-medullary nails and sliding hip screws.

\section{Competing interests}

CB, AS and AJ are employees of Stryker Osteosynthesis, Kiel, Germany, GT is and $C E$ has been consultant to the same company. AJB was employed during the time of data collection by Stryker Osteosynthesis.

\section{Authors' contributions}

AJB carried out the data collection, analysis and participated in manuscript writing. CB participated in study design performed statistical data analysis. AJ and CE participated in data analysis and manuscript writing. AS and GT participated in study design and coordination and help to draft the manuscript. All authors read and approved the final manuscript.

\section{Acknowledgements}

The authors would like to thank Annelore Schreiber and Nils Brose for help with retrieval of patients' notes and radiographs.

\section{Author Details}

1Department of Orthopaedics, Institute of Clinical Sciences at the Sahlgrenska Academy, University of Gothenburg, Gothenburg, Sweden, 2Stryker Osteosynthesis, Kiel, Germany and ${ }^{3}$ Trauma Unit, University Hospital of Strasbourg, Strasbourg, France

Received: 17 October 2009 Accepted: 26 June 2010 Published: 26 June 2010

\section{References}

1. Kuentscher G: Recent advances in the field of medullary nailing. Ann Chir Gynaecol Fenn 1948, 37:1 15.

2. Zickel RE: An intramedullary fixation device for the proximal part of the femur. Nine years' experience. J Bone Joint Surg Am 1976, 58(6):866-872.

3. Halder SC: The Gamma nail for peritrochanteric fractures. J Bone Joint Surg Br 1992, 74(3):340-344.

4. Parker MJ, Pryor GA: Gamma versus DHS nailing for extracapsular femoral fractures. Meta-analysis of ten randomised trials. Int Orthop 1996, 20(3):163-168.

5. Utrilla AL, Reig JS, Munoz FM, Tufanisco CB: Trochanteric gamma nail and compression hip screw for trochanteric fractures: a randomized, prospective, comparative study in 210 elderly patients with a new design of the gamma nail. J Orthop Trauma 2005, 19(4):229-233.

6. Bridle SH, Patel AD, Bircher M, Calvert PT: Fixation of intertrochanteric fractures of the femur. A randomised prospective comparison of the gamma nail and the dynamic hip screw. J Bone Joint Surg Br 1991, 73(2):330-334.

7. Park SR, Kang JS, Kim HS, Lee WH, Kim YH: Treatment of intertrochanteric fracture with the Gamma AP locking nail or by a compression hip screw--a randomised prospective trial. Int Orthop 1998, 22(3):157-160.

8. Lyddon DW Jr: The prevention of complications with the Gamma Locking Nail. Am J Orthop 1996, 25(5):357-363.

9. Curtis MJ, Jinnah RH, Wilson V, Cunningham BW: Proximal femoral fractures: a biomechanical study to compare intramedullary and extramedullary fixation. Injury 1994, 25(2):99-104.
10. Lindsey RW, Teal P, Probe RA, Rhoads D, Davenport S, Schauder K: Early experience with the gamma interlocking nail for peritrochanteric fractures of the proximal femur. J Trauma 1991, 31(12):1649-1658.

11. Heinz T, Vecsei V: [Complications and errors in use of the gamma nail. Causes and prevention]. Chirurg 1994, 65(11):943-952

12. Mahomed N, Harrington I, Kellam J, Maistrelli G, Hearn T, Vroemen J: Biomechanical analysis of the Gamma nail and sliding hip screw. Clin Orthop 1994:280-288.

13. Leung KS, So WS, Shen WY, Hui PW: Gamma nails and dynamic hip screws for peritrochanteric fractures. A randomised prospective study in elderly patients. J Bone Joint Surg Br 1992, 74(3):345-351.

14. Radford PJ, Needoff M, Webb JK: A prospective randomised comparison of the dynamic hip screw and the gamma locking nail. J Bone Joint Surg Br 1993, 75(5):789-793.

15. Platzer $P$, Thalhammer $G$, Wozasek GE, Vecsei V: Femoral shortening after surgical treatment of trochanteric fractures in nongeriatric patients. $J$ Trauma 2008, 64(4):982-989.

16. Hesse B, Gachter A: Complications following the treatment of trochanteric fractures with the gamma nail. Arch Orthop Trauma Surg 2004

17. Adams Cl, Robinson CM, Court-Brown CM, McQueen MM: Prospective randomized controlled trial of an intramedullary nail versus dynamic screw and plate for intertrochanteric fractures of the femur. $J$ Orthop Trauma 2001, 15(6):394-400

18. Albareda J, Laderiga A, Palanca D, Paniagua L, Seral F: Complications and technical problems with the gamma nail. Int Orthop 1996, 20(1):47-50.

19. Parker MJ, Handoll HH: Gamma and other cephalocondylic intramedullary nails versus extramedullary implants for extracapsular hip fractures. Cochrane Database Syst Rev 2004:CD000093.

20. Ahrengart L, Tornkvist H, Fornander P, Thorngren KG, Pasanen L, Wahlstrom P, Honkonen S, Lindgren U: A randomized study of the compression hip screw and Gamma nail in 426 fractures. Clin Orthop 2002:209-222.

21. Anglen JO, Weinstein $\mathrm{JN}$ : Nail or plate fixation of intertrochanteric hip fractures: changing pattern of practice. A review of the American Board of Orthopaedic Surgery Database. J Bone Joint Surg Am 2008, 90(4):700-707.

22. Baumgaertner MR, Curtin SL, Lindskog DM: Intramedullary versus extramedullary fixation for the treatment of intertrochanteric hip fractures. Clin Orthop 1998:87-94.

23. Boriani S, De lure F, Bettelli G, Specchia L, Bungaro P, Montanari G, Capelli A, Canella P, Regnoli R, Triscari C: The results of a multicenter Italian study on the use of the Gamma nail for the treatment of pertrochanteric and subtrochanteric fractures: a review of 1181 cases. Chir Organi Mov 1994, 79(2):193-203.

24. Calvert PT:The Gamma nail--a significant advance or a passing fashion? $J$ Bone Joint Surg Br 1992, 74(3):329-331

25. Chevalley F, Gamba D: Gamma nailing of pertrochanteric and subtrochanteric fractures: clinical results of a series of 63 consecutive cases. J Orthop Trauma 1997, 11(6):412-415.

26. Jiang $S D$, Jiang $L S$, Zhao CQ, Dai LY: No advantages of Gamma nail over sliding hip screw in the management of peritrochanteric hip fractures: a meta-analysis of randomized controlled trials. Disabil Rehabil 2008, 30(7):493-497.

27. Kempf I, Grosse A, Taglang G, Favreul E: [Gamma nail in the treatment of closed trochanteric fractures. Results and indications apropos of 121 cases]. Rev Chir Orthop Reparatrice Appar Mot 1993, 79(1):29-40.

28. Kukla C, Heinz T, Gaebler C, Heinze G, Vecsei V: The standard Gamma nail: a critical analysis of 1,000 cases. J Trauma 2001, 51(1):77-83.

29. Miedel R, Ponzer S, Tornkvist H, Soderqvist A, Tidermark J: The standard Gamma nail or the Medoff sliding plate for unstable trochanteric and subtrochanteric fractures. A randomised, controlled trial. J Bone Joint Surg Br 2005, 87(1):68-75.

30. Pervez H, Parker MJ: Results of the long Gamma nail for complex proximal femoral fractures. Injury 2001, 32(9):704-707.

31. Sehat K, Baker RP, Pattison G, Price R, Harries WJ, Chesser TJ: The use of the long gamma nail in proximal femoral fractures. Injury 2005, 36(11):1350-1354.

32. Valverde JA, Alonso MG, Porro JG, Rueda D, Larrauri PM, Soler JJ: Use of the Gamma nail in the treatment of fractures of the proximal femur. Clin Orthop 1998:56-61. 
33. van den Brink WA, Janssen IM: Failure of the gamma nail in a highly unstable proximal femur fracture: report of four cases encountered in The Netherlands. J Orthop Trauma 1995, 9(1):53-56.

34. Parker MJ, Handoll HH: Gamma and other cephalocondylic intramedullary nails versus extramedullary implants for extracapsular hip fractures in adults. Cochrane Database Syst Rev 2008:CD000093.

35. Rebuzzi E, Pannone A, Schiavetti S, Santoriello P, de Nicola U, Fancellu G, Cau P, Gulli S, Dordolin P, Maniscalco P, et al:: IMHS clinical experience in the treatment of peritrochanteric fractures. The results of a multicentric Italian study of 981 cases. Injury 2002, 33(5):407-412.

36. Heinert G, Parker MJ: Intramedullary osteosynthesis of complex proximal femoral fractures with the Targon PF nail. Injury 2007, 38(11):1294-1299.

37. Lavini F, Renzi-Brivio L, Aulisa R, Cherubino F, Di Seglio PL, Galante N, Leonardi W, Manca M: The treatment of stable and unstable proximal femoral fractures with a new trochanteric nail: results of a multicentre study with the Veronail. Strategies Trauma Limb Reconstr 2008, 3(1):15-22.

38. Simmermacher RK, Bosch AM, Van der Werken C: The AO/ASIF-proximal femoral nail (PFN) a new device for the treatment of unstable proximal femoral fractures. Injury 1999, 30(5):327-332.

39. Krastman $P$, Welvaart WN, Breugem SJ, van Vugt AB: The Holland nail: a universal implant for fractures of the proximal femur and the femoral shaft. Injury 2004, 35(2):170-178.

40. Gill JB, Jensen L, Chin PC, Rafiei P, Reddy K, Schutt RC Jr: Intertrochanteric hip fractures treated with the trochanteric fixation nail and sliding hip screw. J Surg Orthop Adv 2007, 16(2):62-66

41. Ruecker AH, Rupprecht M, Gruber M, Gebauer M, Barvencik F, Briem D, Rueger JM: The treatment of intertrochanteric fractures: results using an intramedullary nail with integrated cephalocervical screws and linear compression. J Orthop Trauma 2009, 23(1):22-30.

42. Muller ME, Nazarian S, Koch P, Schatzker J: The AO Classification of Fractures of Long Bones. new York: Springer; 1990

43. Schipper IB, Steyerberg EW, Castelein RM, van Vugt AB: Reliability of the $\mathrm{AO} / \mathrm{ASIF}$ classification for pertrochanteric femoral fractures. Acta Orthop Scand 2001, 72(1):36-41.

44. Pervez H, Parker MJ, Pryor GA, Lutchman L, Chirodian N: Classification of trochanteric fracture of the proximal femur: a study of the reliability of current systems. Injury 2002, 33(8):713-715.

45. Ruter A, Mayr E: [Pseudarthrosis]. Chirurg 1999, 70(11):1239-1245.

46. Calandruccio RA, Anderson WE: Post-fracture avascular necrosis of the femoral head: correlation of experimental and clinical studies. Clin Orthop Relat Res 1980:49-84.

47. Bellabarba C, Herscovici D Jr, Ricci WM: Percutaneous treatment of peritrochanteric fractures using the Gamma nail. Clin Orthop 2000:30-42.

48. Osnes EK, Lofthus CM, Falch JA, Meyer HE, Stensvold I, Kristiansen IS, Nordsletten L: More postoperative femoral fractures with the Gamma nail than the sliding screw plate in the treatment of trochanteric fractures. Acta Orthop Scand 2001, 72(3):252-256.

49. Schipper IB, Steyerberg EW, Castelein RM, van der Heijden FH, den Hoed PT, Kerver AJ, van Vugt AB: Treatment of unstable trochanteric fractures. Randomised comparison of the gamma nail and the proximal femoral nail. J Bone Joint Surg Br 2004, 86(1):86-94.

50. Butt MS, Krikler SJ, Nafie S, Ali MS: Comparison of dynamic hip screw and gamma nail: a prospective, randomized, controlled trial. Injury 1995, 26(9):615-618

51. Hoffman CW, Lynskey TG: Intertrochanteric fractures of the femur: a randomized prospective comparison of the Gamma nail and the Ambi hip screw. Aust NZ J Surg 1996, 66(3):151-155.

52. Aune AK, Ekeland A, Odegaard B, Grogaard B, Alho A: Gamma nail vs compression screw for trochanteric femoral fractures. 15 reoperations in a prospective, randomized study of 378 patients. Acta Orthop Scand 1994, 65(2):127-130

53. Leung KS, Chen CM, So WS, Sato K, Lai CH, Machaisavariya $B$, Suntharalingam S: Multicenter trial of modified Gamma nail in East Asia. Clin Orthop 1996:146-154.

54. Lacroix H, Arwert H, Snijders CJ, Fontijne WP: Prevention of fracture at the distal locking site of the gamma nail. A biomechanical study. Bone Joint Surg Br 1995, 77(2):274-276.

55. Simmermacher RK, Ljungqvist J, Bail H, Hockertz T, Vochteloo AJ, Ochs $U$, Werken C: The new proximal femoral nail antirotation (PFNA) in daily practice: results of a multicentre clinical study. Injury 2008, 39(8):932-939.

56. Bhandari M, Schemitsch E, Jonsson A, Zlowodzki M, Haidukewych GJ: Gamma nails revisited: gamma nails versus compression hip screws in the management of intertrochanteric fractures of the hip: a metaanalysis. J Orthop Trauma 2009, 23(6):460-464.

57. Robinson CM, Adams Cl, Craig M, Doward W, Clarke MC, Auld J: Implantrelated fractures of the femur following hip fracture surgery. $J$ Bone Joint Surg Am 2002, 84-A(7):1116-1122.

58. Baumgaertner MR, Curtin SL, Lindskog DM, Keggi JM: The value of the tip-apex distance in predicting failure of fixation of peritrochanteric fractures of the hip. J Bone Joint Surg Am 1995, 77(7):1058-1064.

59. Davis TR, Sher UL, Horsman A, Simpson M, Porter BB, Checketts RG: Intertrochanteric femoral fractures. Mechanical failure after internal fixation. J Bone Joint Surg Br 1990, 72(1):26-31.

60. Pervez $\mathrm{H}$, Parker MJ, Vowler S: Prediction of fixation failure after sliding hip screw fixation. Injury 2004, 35(10):994-998

61. Nordin S, Zulkifli O, Faisham Wl: Mechanical failure of Dynamic Hip Screw (DHS) fixation in intertrochanteric fracture of the femur. Med $J$ Malaysia 2001, 56(Suppl D):12-17.

62. Wolfgang GL, Bryant MH, O'Neill JP: Treatment of intertrochanteric fracture of the femur using sliding screw plate fixation. Clin Orthop 1982:148-158

63. Bojan A, Taglang G, Beimel C, Jönsson A, Schnettler R: A retrospective analysis of cut out complications in 3066 patients treated with Gamma Nails. Journal of Orthopaedic Trauma 2004, 18(9):S21.

64. Kannus P, Parkkari J, Sievanen $\mathrm{H}$, Heinonen A, Vuori I, Jarvinen M: Epidemiology of hip fractures. Bone 1996, 18(1 Suppl):57S-63S.

65. Barquet A, Mayora G, Fregeiro J, Lopez L, Rienzi D, Francescoli L: The treatment of subtrochanteric nonunions with the long gamma nail: twenty-six patients with a minimum 2-year follow-up. J Orthop Trauma 2004, 18(6):346-353

66. Singh M, Nagrath AR, Maini PS: Changes in trabecular pattern of the upper end of the femur as an index of osteoporosis. J Bone Joint Surg Am 1970, 52(3):457-467.

67. Holt G, Smith R, Duncan K, Hutchison JD, Gregori A: Outcome after surgery for the treatment of hip fracture in the extremely elderly. Bone Joint Surg Am 2008, 90(9):1899-1905.

68. Al-Ani AN, Samuelsson B, Tidermark J, Norling A, Ekstrom W, Cederholm T, Hedstrom M: Early operation on patients with a hip fracture improved the ability to return to independent living. A prospective study of 850 patients. J Bone Joint Surg Am 2008, 90(7):1436-1442.

\section{Pre-publication history}

The pre-publication history for this paper can be accessed here: http://www.biomedcentral.com/1471-2474/11/133/prepub

doi: 10.1186/1471-2474-11-133

Cite this article as: Bojan et al., 3066 consecutive Gamma Nails. 12 years experience at a single centre BMC Musculoskeletal Disorders 2010, 11:133

\section{Submit your next manuscript to BioMed Centra and take full advantage of:}

- Convenient online submission

- Thorough peer review

- No space constraints or color figure charges

- Immediate publication on acceptance

- Inclusion in PubMed, CAS, Scopus and Google Scholar

- Research which is freely available for redistribution 